\title{
Publications indexed in Medline and Embase originating from the Syrian Arab Republic: a survey \\ H.E. Matar, ${ }^{1}$ M.Q. Almerie, ${ }^{1}$ C.E. Adams ${ }^{2}$ and A. Essali ${ }^{3}$
}

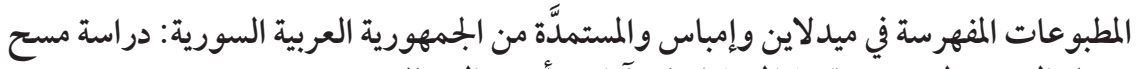

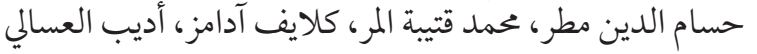

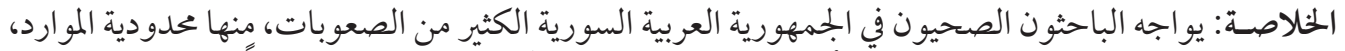

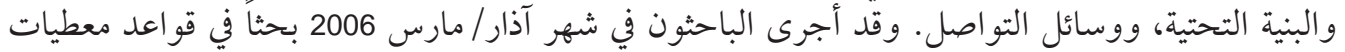

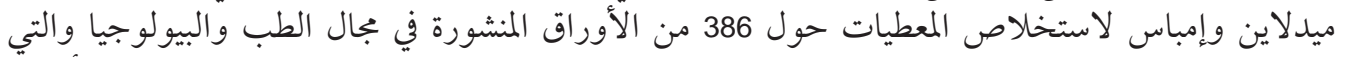

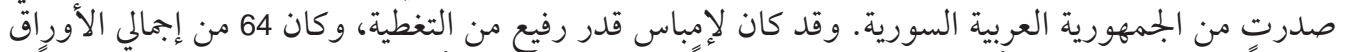

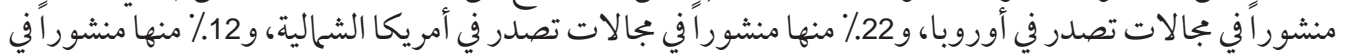

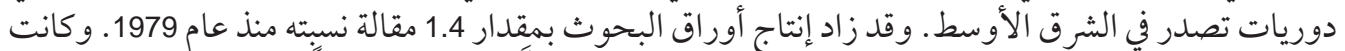

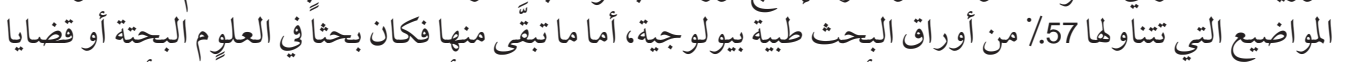

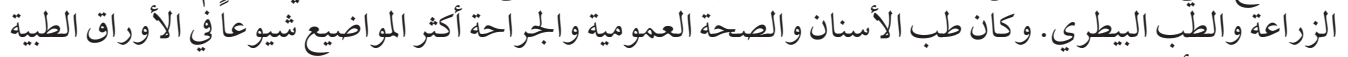

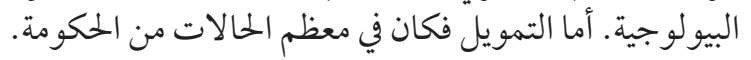

ABSTRACT Health research in the Syrian Arab Republic faces many difficulties, including limited funds, infrastructure and means of dissemination. In a search of Medline and Embase databases in March 2006 we extracted data on 386 biomedical papers originating from the Syrian Arab Republic. Embase had the superior coverage. A total of $64 \%$ were published in journals from Europe, $22 \%$ from North American journals and $12 \%$ in periodicals from the Middle East. Output of papers increased by 1.4 articles/year since 1979 . The topics of $57 \%$ of papers were biomedical, with the remainder being pure science or agricultural/veterinarian issues. Dentistry, public health and surgery were the commonest subjects of the biomedical papers. Funding was largely from government.

\begin{abstract}
Étude sur les publications indexées dans Medline et Embase provenant de la République arabe syrienne

RÉSUMÉ La recherche en santé en République arabe syrienne est confrontée à de nombreuses difficultés, notamment au caractère limité des ressources financières, de l'infrastructure et des moyens de diffusion. Lors d'une recherche dans les bases de données Medline et Embase en mars 2006, nous avons extrait des références relatives à 386 articles biomédicaux provenant de ce pays. La base Embase était celle qui en contenait le plus. Au total, $64 \%$ des articles étaient publiés dans des revues d'Europe, $22 \%$ dans des revues d'Amérique du Nord et $12 \%$ dans des périodiques du Moyen-Orient. Le nombre d'articles publiés avait augmenté de 1,4 article/an depuis 1979. Pour $57 \%$ des articles, le sujet était biomédical, alors que les autres articles traitaient de science pure ou de questions agricoles ou vétérinaires. Les sujets les plus courants des articles biomédicaux étaient la médecine dentaire, la santé publique et la chirurgie. Leur financement provenait en grande partie des pouvoirs publics.
\end{abstract}

\footnotetext{
${ }^{1}$ Faculty of Medicine, University of Damascus, Damascus, Syrian Arab Republic.

${ }^{2}$ Department of Adult Psychiatry, University of Leeds, Leeds, United Kingdom (Correspondence to C.E. Adams: clive.adams@nottingham.ac.uk).

${ }^{3}$ Centre of Psychiatry, Damascus, Syrian Arab Republic.

Received: 13/10/06; accepted: 10/12/06
} 


\section{Introduction}

The Syrian Arab Republic has a population of 18.8 million with a median age of 21 years (compared with 39 years in the United Kingdom) and a growth rate of $2.3 \%$ (UK $0.28 \%$ ). The infant mortality rate is 28.6 deaths/1000 live births (UK 5.1) and the life expectancy at birth is 70.3 years (UK 78.5). The gross domestic product is estimated at US\$ 73.33 billion (UK $\$ 1.83$ trillion).

The structure of modern scientific research in the Syrian Arab Republic started to take shape in 1958 when the Higher Council of Science was established [1]. Research work in this country, however, faces difficulties such as low budgets and limited research capacity. Nevertheless, single centres have conducted research, although collaborative work between Arab universities or with international organizations is also evident $[2,3]$.

Wide dissemination of research is a problem. Much biomedical research is published in specialist periodicals produced by local universities and not covered by bibliographic databases such as Medline, the most widely accessible database, produced by the National Library of Medicine in the United States of America [4]. Coverage is worldwide, but most records are from English language sources or have English abstracts. Embase is a European-based general biomedical database containing records of the contents of over 5000 international biomedical journals. It has been claimed that Embase provides greater coverage of non-English language publications and broader coverage of pharmaceuticals, psychiatry, toxicology and alternative medicine than Medline alone. The estimated overlap between Medline and Embase is only $30 \%-50 \%$, and searchers comparing the 2 databases concluded that relevant information would be missed if only one of the databases was searched [5].
The objectives of the study were to produce a survey of widely accessible research publications from the Syrian Arab Republic.

\section{Methods}

We searched PubMed (http://www.ncbi. nlm.nih.gov/entrez/) in March 2006 using the search phrase "Syria\$" in the affiliation field. This same search was then repeated for Embase (Ovid). Downloaded data from both databases were then merged in a bibliographic citation program (ProCite). Two authors (M.Q.M., H.E.M.), working independently, discarded duplicates, inspected all electronic records and extracted data on source database, periodical and research centre, the broad category of study methodology, biomedical specialty, source of funding and year of publication. Disagreement was resolved by discussion.

\section{Results}

The initial search resulted in a total of 492 records (163 duplicates). Duplicated records were removed, 17 other papers were excluded because they were not conducted in the Syrian Arab Republic, and another 7 records were discarded as they had been conducted by Syrian researchers outside of the country. Finally, 386 Medline or Embase reports seemed to be papers genuinely originating in the Syrian Arab Republic. Of these $47 \%$ were exclusively from Embase, $32 \%$ from Medline alone and $21 \%$ were cited in both databases.

The first publication we identified was in 1979. Thereafter the number of publications from the Syrian Arab Republic accessible in these widely used databases has increased sharply, particularly in recent years, with an overall rate of increase of 1.4 articles/ annum since 1979 (Figure 1).

المجلة الصحية لشرق المتوسط، منظمة الصحة العالمية، المجلد الخنامس عشر، العدد ب، 9 +. 


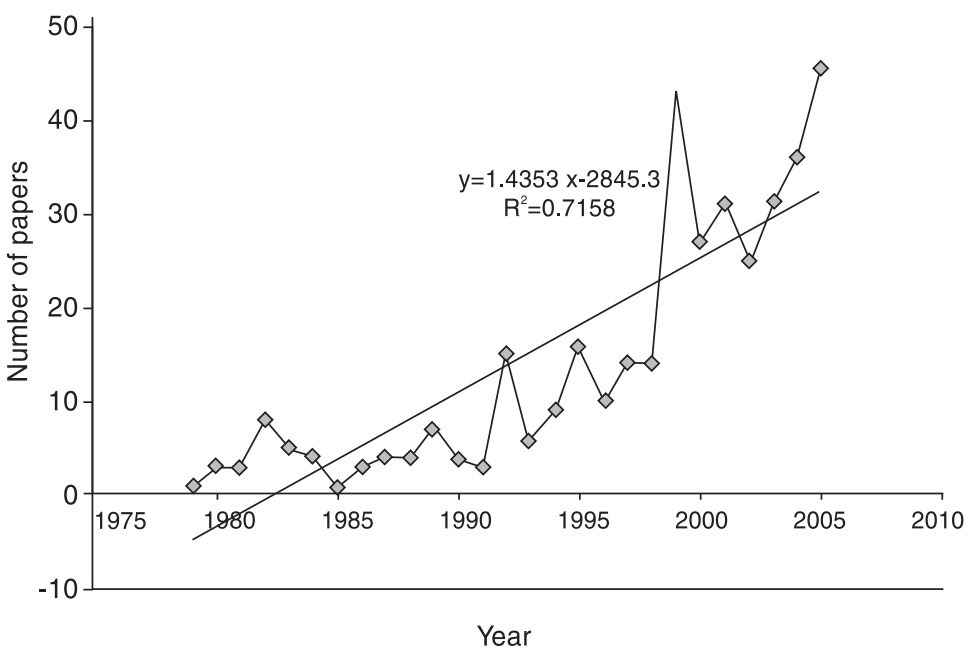

Figure 1 Research papers indexed in Medline and Embase originating from the Syrian Arab Republic over time

Most papers (247, 64\%) were published in journals clearly originating from Europe. Within Europe, Syrian papers were most commonly found in British (110), Dutch (32), German (32) or Hungarian (30) periodicals. About a quarter (22\%) of the papers were published in North American journals. Periodicals from the Middle East had published $12 \%$ of the papers and journals from Asia, Australia and New Zealand only $2 \%$. Overall, the papers were published in 185 different journals; the medical journals that most commonly published work from the Syrian Arab Republic were the Eastern Mediterranean health journal (15 papers) and the Saudi medical journal (13 papers).

The majority of contact addresses were in the capital, Damascus (68\%), but Aleppo, the industrial capital, was the source of $25 \%$ of papers. The remainder gave an address in Homs (3\%), Lattakia (2\%) and Hama (1\%); $1 \%$ did not name a specific city.

When classified by the methods or type of paper, $6 \%$ seemed to be randomized or possibly randomized clinical trials and another $5 \%$ were non-randomized clinical studies, $10 \%$ of papers seemed to be surveys and $13 \%$ were case reports and case series, but $38 \%$ seemed to be purely descriptive. Reviews and editorials made up $16 \%$ and $2 \%$ of papers respectively. It was difficult to classify the methods or type of paper for $9 \%$ of papers.

The biomedical field was heavily represented in our sample (219 of the 386 papers, 57\%) (Table 1), although $31 \%$ were papers on pure science and $11 \%$ were on topics of agricultural or veterinarian interest.

Most papers acknowledged funding from government ministries (Ministry of Higher Education 144 papers, Health 54 papers, Agriculture 43 papers and Defence 17 papers, and the Atomic Energy Commission 114 papers) and 40 acknowledged support from other sources including the private sector. 
Table 1 Numbers of research papers indexed in Medline and Embase originating from the Syrian Arab Republic by biomedical specialty

\begin{tabular}{lcc}
\hline Specialty & $\begin{array}{c}\text { No. of } \\
\text { papers }\end{array}$ & $\begin{array}{c}\text { \% of all } \\
\text { papers } \\
\text { ( } \boldsymbol{n}=\mathbf{3 8 6} \text { ) }\end{array}$ \\
\hline Dentistry & 41 & 11 \\
Public health & 36 & 9 \\
Surgery & 28 & 7 \\
Dermatology & 15 & 4 \\
Cardiology & 14 & 4 \\
Laboratory & 11 & 3 \\
Urology & 11 & 3 \\
Gastroenterology & 7 & 2 \\
Medical history & 7 & 2 \\
Genetics & 7 & 2 \\
Obstetrics \& & 7 & 2 \\
$\quad$ gynaecology & & 2 \\
Ophthalmology & 6 & 2 \\
Rheumatology & 6 & 1 \\
Chest medicine & 5 & 1 \\
Microbiology & 5 & 1 \\
Paediatrics & 5 & 1 \\
Anaesthesia & 3 & 1 \\
Neurology & 2 & 0 \\
Otology & 1 & 0 \\
Oncology & 1 & 0 \\
Psychiatry & 1 &
\end{tabular}

\section{Discussion}

Medline searches inadequately reflected the extent of biomedical publications originat- ing from the Syrian Arab Republic, and Embase had the superior coverage, but it is likely that our simple search has failed to identify other work from this region. No local bibliographic databases are available for comparison.

Nevertheless, this study highlights the wide publishing activity that is burgeoning in the Syrian Arab Republic. This is a growing research community that repeatedly succeeds in overcoming considerable difficulties and barriers to publish in widely disseminated journals. Although this activity is still largely focused in centres in Damascus, work from other cities is also evident. The majority of these published studies were discursive, but we found numbers of case series, cohort surveys and controlled trials. It is clear that researchers in the Syrian Arab Republic do have experience in all the key epidemiological methodologies and it seems likely that future years will bring yet more studies undertaken locally with, hopefully, findings clearly applicable to people in the Syrian Arab Republic.

\section{Acknowledgements}

We would like to thank Dr Naser Al-Merie, Dr Najwa Hakim, Mr Yahya Matar and Mrs Hind Al-Halabi for their support.

\section{References}

1. Kharouf H. Report on scientific research in the Syrian Arab Republic. Damascus, Syrian Arab Republic, Ministry of Higher Education, 1997.

2. Statistics on Scientific Research in the Syrian Arab Republic. Damascus, Syrian Arab Republic, Ministry of Higher Education, 1998.
3. Moufti A. Exchange of information about scientific research in the Arab world: the Syrian paper. Paper presented at the Economic and Social Commission for Western Asia (ESCWA) Meeting on Management of Science and Research Programs, Damascus, Syrian Arab Republic, 1998.

المجلة الصحية لشرق المتوسط، منظمة الصحة العالمية، المجلد الخامس عشر، العدد ب، 9 +. 
4. Fact Sheet MEDLINE®. United States National Library of Medicine [website] (http://www.nlm.nih.gov/pubs/factsheets/ medline.html, accessed 18 August 2008).
5. Wong SS, Wilczynski NL, Haynes RB. Developing optimal search strategies for detecting clinically sound treatment studies in Embase. Journal of the Medical Library Association, 2006; 94:41-7.

\section{Eastern Mediterranean Advisory Committee for Health Re- search}

The Eastern Mediterranean Advisory Committee for Health Research (EM ACHR) comprises senior and outstanding researchers from the Region and represents a balanced disciplinary and geographical distribution. They serve in their individual capacity for a term of three to four years (sometimes extendable). The Committee has the mandate to provide advice to the Regional Director (as deemed necessary by him) on all issues and matters related to health research and development in the Region. The Committee performs its consultative mandate in accordance with its terms of reference, given to it by the Regional Director.

Further information can be found at the Research Policy and Cooperation website: http://www.emro.who.int/rpc/ACHR.htm\#section3 